\title{
Response of herbivorous fishes to crown-of-thorns starfish Acanthaster planci outbreaks. II. Density and biomass of selected species of herbivorous fish and fish-habitat correlations
}

\author{
Anthony M. Hart ${ }^{1,2, *}$, David W. Klumpp ${ }^{1}$, G. R. Russ ${ }^{2}$ \\ 'Australian Institute of Marine Science, PMB No. 3, Townsville M.C., Queensland 4810, Australia \\ ${ }^{2}$ James Cook University of North Queensland, Townsville, Queensland 4811, Australia
}

\begin{abstract}
Density, biomass and fish-habitat correlations were estimated for selected species of herbivorous fish on crown-of-thorns starfish (COTS) impacted and control reefs in the central Great Barrier Reef. The objective was to investigate a long-term numerical and/or biomass response to increased food availability (algal turfs) on COTS affected reefs. Out of 14 variates investigated, 2 showed evidence of a numerical response on COTS affected reefs. Importantly, total number of individuals and total biomass showed no response. Instead, a negative effect (i.e. higher abundances on control reefs) was detected for Zebrasoma scopas, although this was attributable to very high abundances on one of the non-impacted reefs (Coil). Density of Siganus corallinus was higher on COTS impacted reefs; however, this was not greater than variability over time. On COTS affected reefs, there was a negative correlation of herbivorous fish with thick turf algal abundance and a positive correlation with live coral cover, whereas on non-affected reefs, there were a similar number of positive and negative correlations with thick turf algae and live coral. Additionally, a distinct cross-shelf trend in length frequency of Acanthurus nigrofuscus was observed. Differences in food availability, wave energy and intraspecific competition were hypothesized to be important factors in this observed distribution.
\end{abstract}

KEY WORDS: Herbivorous fish - Coral reefs . Crown-of-thorns starfish Numerical response - Fishhabitat correlations - Acanthurus nigrofuscus - Natural disturbance

\section{INTRODUCTION}

Natural disturbance can be as important as competition or succession in structuring coral reef community dynamics (Connell 1978, Pickett \& White 1985). In particular, Hughes (1989) illustrated how the interplay between a major disturbance and competitive interactions shaped community dynamics on a coral reef even though the events were unrelated and occurred years apart. Thus, realistic predictions regarding the role of disturbance in structuring coral reef communities will need to incorporate both equilibrial and nonequilibrial dynamics (sensu Connell 1978) and must

- Present address: ICLARM Coastal Aquaculture Centre, PO Box 438, Honiara, Solomon Islands. E-mail: iclarm@ffa.gov.sb depend on the question being asked and the required level of resolution (Karlson \& Hurd 1993).

Mass mortality of the sea urchin Diadema antillarum in the Caribbean Sea (Lessios et al. 1984, Bak 1985. Hughes et al. 1985, 1987, de Ruyter van Steveninck \& Bak 1986, Liddell \& Ohlhorst 1986, Carpenter 1988. 1990a, Lessios 1988a, 1988b) resulted in the most detailed account of indirect or secondary effects of disturbance on herbivorous fish of coral reefs. With the local near-extinction of this competitor, food (algal) abundance and biomass increased dramatically and there was an immediate increase in grazing rates of roving herbivorous fish (Carpenter 1990b). Subsequent increases in abundance occurred (Carpenter 1990b), leading to the conclusion that herbivorous fish were food-limited prior to the mortality of $D$. antillarum 
(Robertson 1991). More importantly, the timing and sequence of this response varied considerably, in some instances being delayed a considerable time after the increases in algal abundance (Robertson 1991).

At an inter-reefal scale, a number of studies have investigated the effects of COTS (crown-of-thorns starfish) outbreaks on herbivorous coral reef fishes, with contrasting results. In the short term (18 mo post-impact), Williams (1986) found no numerical response of herbivorous fish to increased abundance of the turf algal resource on the Great Barrier Reef (GBR). Williams (1986) noted that with a more powerful test and a longer-term analysis, further changes might have been detected, particularly if focused on individual species. Sano et al. $(1984,1987)$ obtained results similar to those of Williams (1986), while Bouchon-Navaro \& Harmelin-Vivien (1985) detected increases in abundances of herbivorous butterflyfish. In American Samoa, Wass (1987) demonstrated a substantial increase in numbers of larger, roving herbivorous fishes (acanthurids, scarids, siganids).

On a smaller experimental scale, a number of studies have investigated effects of changes in food abundance on herbivorous reef fish within the GBR (Sammarco 1983, Wilkinson \& Sammarco 1983, Russ 1987 Scott \& Russ 1987, Klumpp \& Polunin 1989, Polunin \& Klumpp 1992). Most, however, have focused on the effects of damselfish grazing and territoriality on algal community structure and function. In this study, it is proposed that on COTS affected reefs it is the larger, roving herbivorous grazers (Acanthuridae, Scaridae and Siganidae) which may benefit most from increased resources of turf algae, due to their roving behaviour and large home ranges. If the populations of these fish are principally resource-limited, it is hypothesized that this will be reflected in higher abundances and biomass of such fish on COTS affected reefs as opposed to on controls (non-affected reefs). It is also hypothesized that there will be strong positive associations between these fish and abundance of algal turfs. Focus is on selected individual species, and to this end a specific sampling unit has been developed (Hart unpubl. data).

\section{MATERIALS AND METHODS}

The study was carried out on the windward reef slopes of 3 COTS affected and 3 control reefs in the central region of the GBR. For a full description, refer to Hart \& Klumpp (1996 - this issue).

Data collection. Seven species of roving herbivorous fish were selected for analysis of density and biomass. These were Acanthurus nigrofuscus and Zebrasoma scopas (Acanthuridae), Scarus frenatus, Chlorurus sordidus, and Scarus niger (Scaridae), and Siganus corallinus and Siganus vulpinus (Siganidae). All density and biomass surveys were carried out at 3 to $7 \mathrm{~m}$ depth on the windward reef slope. From a pilot study, the optimum transect size was found to be $45 \times 6 \mathrm{~m}$ (Hart unpubl. data). The procedure involved 2 SCUBA divers. At the start of each transect, the tape was attached to the substratum, and the width of the transect measured to enable the observer (A.M.H.) to 'get their eye in' The observer then swam slowly $\left(\sim 10 \mathrm{~m} \mathrm{~min}^{-1}\right)$, estimating size classes and counting all fish $3 \mathrm{~m}$ (estimated visually) on either side of the transect as it was being laid out. To aid in classifying individuals into particular size classes, a $40 \mathrm{~cm}$ steel ruler with clear gradations was used. Size class categories for the acanthurids were $6-9,9-12,12-15,15-18$, and $>18 \mathrm{~cm}$. The scarids and siganids were classified into slightly larger size classes. These were $10-14,14-18,18-22,22-26,26-30,30-34$ and $>34 \mathrm{~cm}$. At the completion of the density and size class survevs, the rerorder swam back along the transect measuring substratum cover (Hart \& Klumpp 1996), while a second diver wound up the tape. The weight for each individual was estimated using a length-weight regression for each species, and total biomass for each transect was calculated.

Sampling design and data analysis. Sampling design was described in Hart \& Klumpp (1996). From the pilot study, it was estimated that at least 60 replicate sites were required to detect a $20 \%$ difference in total fish abundance between impacted and non-impacted reefs with power $(1-\beta)>0.8$. However, to obtain adequate temporal replication against which spatial patterns could be compared, surveys were repeated on 3 accasions (108 sites). Density and biomass were analyzed with a 4 -factor, mixed-model ANOVA (Hart \& Klumpp 1996). Siganids were omitted from analysis of biomass as they comprised only a small percentage ( $8 \%)$ of total numbers.

To establish the power of the ANOVA in detecting a 'true' difference in abundance between COTS affected and non-affected reefs, minimal detectable differences (MDDs) were estimated for any non-significant results. Methodology follows Zar (1984; p 170-175), and MDDs were calculated for 3 levels of power $(1-\beta), 0.8,0.9$, and 0.95 at $\alpha=0.05$

Fish-benthos correlations. Spearman rank correlation coefficients were calculated between abundance and biomass of each fish species and the different physiognomic categories of substratum cover. Analyses were carried out separately for impacted and nonimpacted reefs on pooled totals (across occasions; $\mathrm{n}=162$ ), and individually for each reef (pooled across occasions; $\mathrm{n}=54$ ). Correlations were also calculated for impacted (Grub, Yankee, Dip) and non-impacted (Centipede, Coil, Bowl) reefs on each occasion ( $\mathrm{n}=54$ ) Because of the large number of individual rank correlation tests (910), only the significant results are sum- 
Table 1. ANOVA results for total numbers and densities of individual species

\begin{tabular}{|c|c|c|c|c|c|c|c|c|c|c|c|c|c|}
\hline Source of variability & $\mathrm{df}$ & MS & $F$ & $\mathrm{p}$ & MS & $F$ & $\mathrm{p}$ & MS & $F$ & $p$ & $\mathrm{MS}$ & $F$ & $\mathrm{p}$ \\
\hline & & \multicolumn{3}{|c|}{ Total no. individuals } & \multicolumn{3}{|c|}{ Acanthurus nigrofuscus } & \multicolumn{3}{|c|}{ Zebrasoma scopas } & \multicolumn{3}{|c|}{ Scarus frenatus } \\
\hline Occasions & 2,90 & 2664.6 & 14.6 & $\cdots$ & 1827.8 & 12.4 & $\cdots$ & 0.067 & 0.27 & ns & 12.72 & 2.28 & ns \\
\hline COTS status & 1,90 & 382.4 & 2.10 & ns & 0.69 & 0.00 & $\mathrm{~ns}$ & 4.343 & 17.3 & $\cdots$ & 3.57 & 0.64 & $\mathrm{~ns}$ \\
\hline Reefs & 4,90 & 12395 & 67.9 & $\cdots$ & 11296 & 77 & $\cdots$ & 7.075 & 28.2 & $\cdots$ & 58.1 & 10.4 & $\cdots$ \\
\hline Occasions $\times$ COTS & 2,90 & 97.6 & 0.53 & ns & 18.29 & 0.12 & ns & 0.076 & 0.30 & ns & 1.67 & 8.3 & ns \\
\hline Occasions $\times$ Reefs & 8,90 & 354.1 & 1.94 & ns & 275.2 & 1.87 & ns & 0.093 & 0.37 & ns & 8.36 & 1.5 & ns \\
\hline Sites & 90,216 & 182.5 & 2.20 & $\cdots$ & 146.8 & 2.87 & $\cdots$ & 0.251 & 4.21 & $\cdots$ & 5.58 & 1.42 & . \\
\hline \multirow[t]{2}{*}{ Residual } & 216 & 82.9 & & & 51.1 & & & 0.060 & & & 3.93 & & \\
\hline & & \multicolumn{3}{|c|}{ Scarus niger } & \multicolumn{3}{|c|}{ Chlorurus sordidus } & \multicolumn{3}{|c|}{ Siganus corallinus" } & \multicolumn{3}{|c|}{ Siganus vulpinus ${ }^{a}$} \\
\hline Occasions & 2,90 & 4.56 & 0.77 & ns & 0.427 & 3.63 & $\cdot$ & 0.535 & 8.4 & $\cdots$ & 0.048 & 1.66 & ns \\
\hline COTS status & 1,90 & 12.3 & 2.07 & ns & 0.008 & 30.07 & ns & 0.726 & 11.4 & - & 0.038 & 0.75 & ns \\
\hline Reefs & 4,90 & 90.6 & 15.3 & $\cdots$ & 1.197 & 10.2 & $\cdots$ & 0.783 & 12.3 & $\cdots$ & 0.97 & 19.1 & $\cdots$ \\
\hline Occasions $\times$ COTS & 2,90 & 3.32 & 0.54 & ns & 0.010 & 0.09 & ns & 0.19 & 2.99 & ns & 0.09 & 0.88 & ns \\
\hline Occasions $\times$ Reefs & 8,90 & 5.63 & 0.95 & ns & 0.161 & 1.38 & $\mathrm{~ns}$ & 0.207 & 3.25 & '. & 0.016 & 0.32 & ns \\
\hline Sites & 90,216 & 5.93 & 1.61 & $\cdot \cdot$ & 0.117 & 1.57 & $\cdots$ & 0.064 & 1.03 & ns & 0.051 & 1.47 & \\
\hline Residual & 216 & 3.68 & & & 0.075 & & & 0.062 & & & 0.034 & & \\
\hline
\end{tabular}

marised. Number of significant correlations due to Type I error $(0.05 \times$ number of comparisons) was subtracted from observed significant correlations to estimate actual number of significant correlations.

\section{RESULTS}

\section{Analysis of densities}

Two species, Zebrasoma scopas and Siganus corallinus, differed significantly in abundance between impacted and control reefs (Table 1). Z. scopas had higher densities on control reefs, while $S$. corallinus was greater in number on affected reefs (Fig. 1). Total numbers and abundances of each of the other species were similar between affected and non-affected reefs. Additionally, distinct temporal trends in abundance of most species occurred and are summarised in Fig. 1.

Highest densities of roving herbivores were found at Bowl and Dip, while Grub and Centipede had the lowest (Fig 1). Densities of Acanthurus nigrofuscus showed the same pattern as total numbers, as this species comprised $52 \%$ of all individuals. Zebrasoma scopas was far greater in abundance on Coil than on any of the other reefs (Table 1; Fig. 1). Scarus frenatus was found in highest densities on Dip, Bowl and Coil, and at lower densities on Yankee and Centipede (Table 1; Fig. 1). S. niger showed exactly the opposite pattern, being highest in abundance on Yankee, Centipede and Grub, and lowest on Coil, Dip and Bowl. Chlorurus sordidius had highest densities on Yankee, Bowl, and Grub, and lowest on Dip and Centipede (Table 1; Fig. 1). Siganus corallinus and $S$. vulpinus were greater in abun-

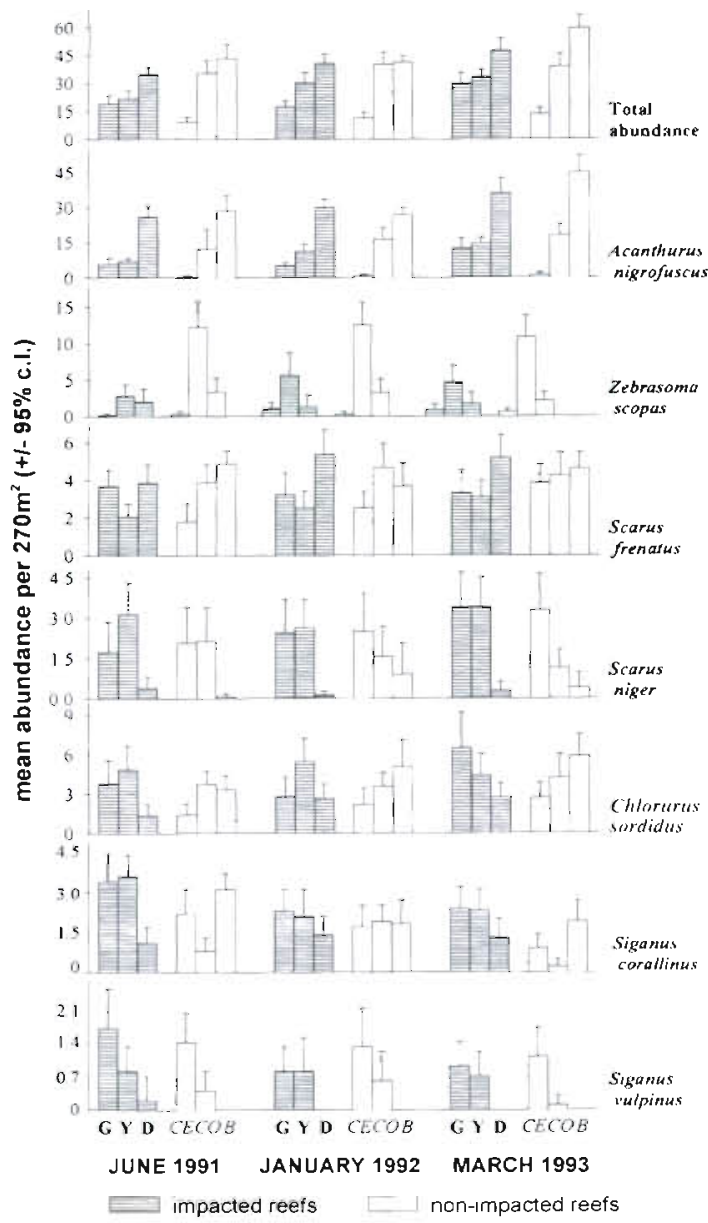

Fig. 1. Mean total abundance and density of all species of roving herbivorous fish during each sampling occasion for impacted ( $\square$ ) and non-impacted $(\square)$ reefs. G: Grub,

Y: Yankee, D: Dip, CE: Centipede, CO: Coil, B: Bowl 
Table 2. ANOVA results for total biomass and biomass of individual species

\begin{tabular}{|c|c|c|c|c|c|c|c|c|c|c|}
\hline Source of variability & $\mathrm{df}$ & MS & $F$ & $\mathrm{p}$ & MS & F & $\mathrm{p}$ & MS & $F$ & $p$ \\
\hline & & \multicolumn{3}{|c|}{ Total biomass } & \multicolumn{3}{|c|}{ Acanthurus nigrofuscus } & \multicolumn{3}{|c|}{ Zebrasoma scopasa } \\
\hline Occasions & 2,90 & 20.52 & 1131 & $\cdots$ & 10.57 & 22.8 & $\cdots$ & 00195 & 2.05 & ns \\
\hline COTS Status & 1,90 & 1.75 & 0.96 & ns & 1.832 & 3.95 & $\cdot$ & 0.119 & 12.51 & $\cdots$ \\
\hline Reefs & 4,90 & 66.56 & 36.7 & $\cdots$ & 36.82 & 79.4 & $\cdots$ & 0.234 & 24.6 & $\cdots$ \\
\hline Occasions $\times$ COTS & 2,90 & 0.79 & 0.45 & $\mathrm{~ns}$ & 0.448 & 0.96 & ns & 0.0036 & 0.38 & ns \\
\hline Occasions $\times$ Reefs & 8,90 & 4.39 & 2.42 & $\cdot$ & 1.621 & 3.49 & $\cdots$ & 0.006 & 0.63 & ns \\
\hline Sites & 90,216 & 1.82 & 1.57 & $\cdots$ & 0.464 & 2.39 & $\cdots$ & 0.0095 & 3.54 & $\cdots$ \\
\hline \multirow[t]{2}{*}{ Residual } & 216 & 1.16 & & & 0.194 & & & 0.0027 & & \\
\hline & & \multicolumn{3}{|c|}{ Scarus frenatus } & \multicolumn{3}{|c|}{ Scarus niger } & \multicolumn{3}{|c|}{ Chlorurus sordidus } \\
\hline Occasions & 2,90 & 0.66 & 0.89 & ns & 0.00329 & 0.18 & ns & 36.41 & 1.55 & ns \\
\hline COTS Status & 1,90 & 0.56 & 0.82 & ns & 0.019 & 1.02 & ns & 2.734 & 0.12 & ns \\
\hline Reefs & 4,90 & 6.75 & 9.2 & $\cdots$ & 0.263 & 14.16 & $\cdots$ & 172.8 & 7.35 & $\cdots$ \\
\hline Occasions $\times$ COTS & 2,90 & 0.047 & 0.06 & ns & 0.0183 & 0.99 & ns & 8.45 & 0.36 & hS \\
\hline Occasions $\times$ Reefs & 8,90 & 0.80 & 1.09 & $\mathrm{~ns}$ & 0.0082 & 0.44 & ns & 17.54 & 0.75 & ns \\
\hline Sites & 90,216 & 0.73 & 1.50 & $\cdots$ & 0.0186 & 1.47 & $\cdot$ & 23.53 & 1.62 & $\cdots$ \\
\hline Residual & 216 & 0.49 & & & 0.0127 & & & 14.56 & & \\
\hline
\end{tabular}

dance on Grub and Yankee, and Centipede and Grub respectively, while $S$. corallinus appeared in fewer numbers on Dip and Coil. S. vulpinus was absent at Bowl and very low in number at Dip (Fig. 1).

\section{Analysis of fish biomass}

Patterns in biomass were very similar to those for densities, with the following exceptions. There was a significant effect of COTS status on biomass of Acanthurus nigrofuscus (Table $2 ; \mathrm{p}=0.0499$ ); however, Tukey's test did not detect a difference between affected and non-affected reefs. A significant interaction of occasions and reefs occurred for both total biomass and biomass of $A$. nigrofuscus (Table 2). Total biomass was consistent across all occasions at Grub, Yankee, Centipede and Coil; however, it changed over time at Dip and Bowl. Biomass of A. nigrofuscus did not change at Coil or Centipede over the 3 sampling occasions. At Grub, Yankee, Dip and Bowl, it was highest in March 1993 and lowest in June 1991.

\section{Power analysis}

For the COTS status effect, the ANOVA had a minimal detectable difference of 15, 17, and 19\% (of the mean of COTS impacted and non-impacted reefs) for total abundance at a power of $0.8,0.9$ and 0.95 respectively (Table 3). For Acanthurus nigrofuscus, the MDDs were 25,29 and $33 \%$, similar to those of Scarus frenatus. The test was less powerful for $S$. niger, although still capable of detecting a $48 \%$ difference in density. MDDs for biomass were similar to those for density (Table 3).

\section{Size class structure}

Observation of the size structure of each species yields some additional information on patterns of abundance and biomass. In March 1993, large numbers of Scarus niger and Chlorurus sordidus appeared in the smallest size classes at Grub and Centipede reefs (Fig. 2). For Acanthurus nigrofuscus, a distinct

Table 3. Minimal detectable differences (MDDs) of densities and biomass of herbivorous fish for non-significant results of COTS status effect. MDDs are calculated at 3 levels of power $(1-\beta, 0.8,0.9$ and 0.95$)$ and expressed as \% of the mean density and biomass found at impacted and non-impacted reefs

\begin{tabular}{|c|c|c|c|c|c|c|c|}
\hline \multirow[t]{2}{*}{ Species } & \multicolumn{2}{|c|}{ MDDs $(\%$ of mear } & \multirow{2}{*}{$\begin{array}{c}\text { Density } \\
0.95\end{array}$} & \multirow[t]{2}{*}{ Species } & \multicolumn{3}{|c|}{ MDDs ( $\%$ of mean) Biomass } \\
\hline & 0.8 & 0.9 & & & 0.8 & 0.9 & 0.95 \\
\hline Total numbers & 1.5 & 17 & 19 & Total biomass & 1.4 & 17 & 19 \\
\hline Acanthurus nigrofuscus & 25 & 29 & 33 & & & & \\
\hline Scarus frenatus & 22 & 25 & 29 & Scarus frenatus & 25 & 29 & 33 \\
\hline Scarus niger & 48 & 55 & 62 & Scarus niger & 54 & 62 & 70 \\
\hline Chlorurus sordidus & 35 & 40 & 45 & Chlorurus sordidus & 32 & 38 & 41 \\
\hline
\end{tabular}




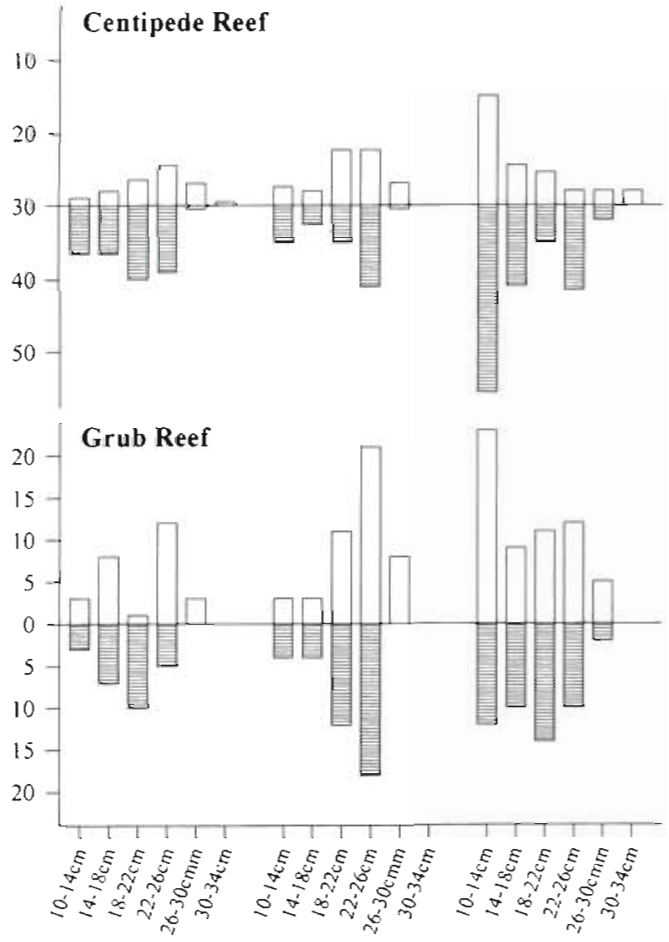

JUNE 1991 JANUARY 1992 MARCH 1993

Scarus niger Chlorurus sordidus

Fig. 2. Scarus niger and Chlorurus sordidus. Length frequency at Grub and Centipede reefs, June 1991, January 1992 and March 1993

shift in size structure across the continental shelf was observed (Fig. 3), and this was evident on all sampling occasions. At the exposed outer-shelf reefs of Coil and Dip, most individuals occurred in the smaller size range. However, the mid-shelf reefs of Grub and Centipede contained predominantly larger individuals of $A$. nigrofuscus. Size distribution at Bowl and Yankee was between these 2 extremes.

\section{Fish-substrate correlations}

Approximately equal numbers of significantly positive and negative correlations occurred between the 7 species of fish and fine turf algal cover on impacted and control reefs (Table 4). However, for thick turf algae on affected reefs, there were 4 times as many negative as positive correlations with densities and biomass of herbivorous fish. Density and biomass of Zebrasoma scopas showed a consistent negative correlation with fine and thick algal turfs at all reefs (Table 4). Conversely, Siganus corallinus had a consistent positive correlation with thick turfs at all reefs.

On impacted reefs, there were 28 significantly positive correlations between density and biomass of fish and live coral cover (Table 4), and 2 negative correlations. On non-impacted reefs, this large disparity did not occur. There were, however, a greater number of significantly positive correlations with live coral (11) as opposed to negative correlations (6). Again, Zebrasoma scopas was consistent, showing only positive correlations with live coral cover at both impacted and non-impacted reefs.

Correlations between density or biomass of herbivorous fish and coralline algae also showed differences between affected and control reefs (Table 4). On impacted reefs, there were a similar number of significantly positive correlations (10) and negative correlations (11) But on non-impacted reefs, there were a far greater number of positive correlations with coralline algae (21) than negative correlations (4)

To summarise, densities of Siganus corallinus were higher on COTS affected reefs. However, the majority of patterns in abundance and biomass of herbivorous fish were not influenced by the COTS status of the reef. There was also no evidence for increased positive correlations of density or biomass with algal turfs on

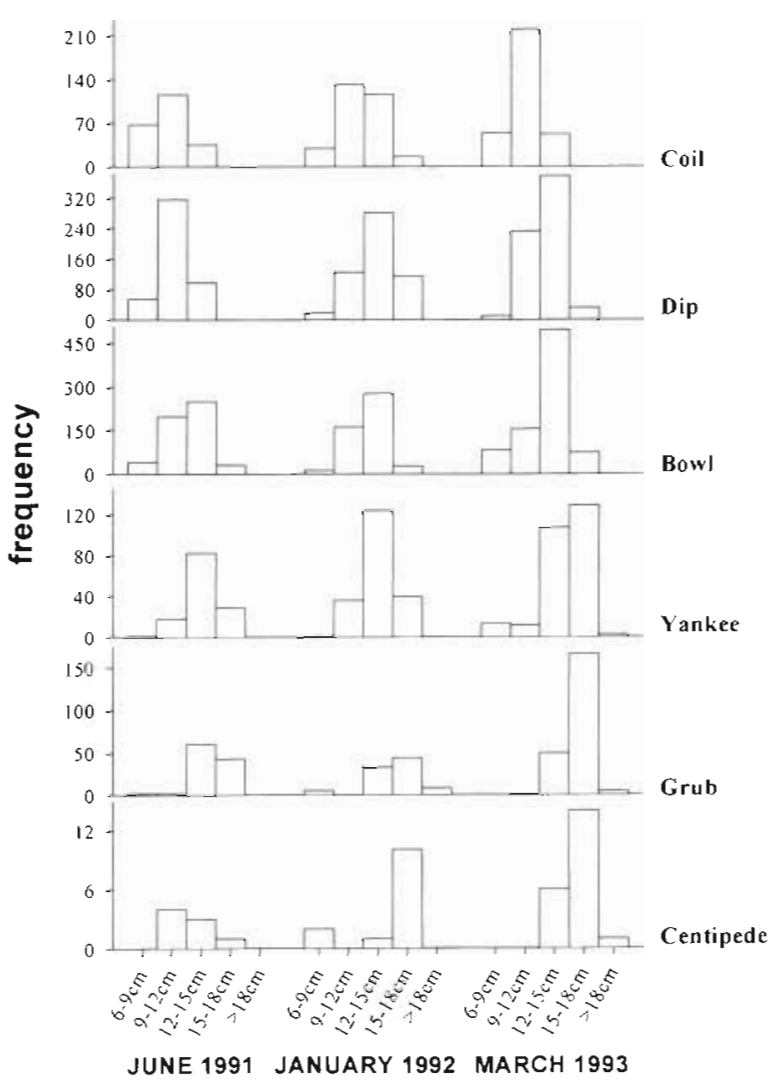

Fig. 3. Acanthurus nigrofuscus. Cross-shelf pattern in lengthfrequency distribution as observed on 3 separate occasions. Data are arranged in order from the most exposed outer-shelf reef of Coil to the more sheltered mid-shelf reefs of Grub and Centipede 
Table 4. Summary of significant Spearman rank correlations $(p<0.05)$ between density and biomass of herbivorous fish and different physiognomic categories of substrate cover. Results are split into both positive and negative correlations. For each category, a total of 91 correlations were calculated. Thus, the number of expected significant differences due to Type 1 error $(\alpha=0.05)$ was 4 . Numbers in parentheses represent adjusted totals after accounting for Type 1 error

\begin{tabular}{|c|c|c|c|c|c|c|c|c|}
\hline \multirow[t]{4}{*}{ Species } & \multicolumn{8}{|c|}{ Number of significant correlations } \\
\hline & \multicolumn{4}{|c|}{ Fine turf́ algae } & \multicolumn{4}{|c|}{ Thick turf algae } \\
\hline & \multicolumn{2}{|c|}{ Impacted } & \multicolumn{2}{|c|}{ Control } & \multicolumn{2}{|c|}{ Impacted } & \multicolumn{2}{|c|}{ Control } \\
\hline & Positive & Negative & Positive & Negative & Positive & Negative & Positive & Negative \\
\hline Total numbers & 1 & 1 & 0 & 0 & 0 & 3 & 2 & 0 \\
\hline Acanthurus nigrofuscus & 2 & 2 & 1 & 0 & 0 & 2 & 3 & 0 \\
\hline Zebrasoma scopas & 0 & 0 & 0 & 4 & 0 & 1 & 0 & 5 \\
\hline Scarus frenatus & 0 & 1 & 1 & 0 & 0 & 0 & 1 & 0 \\
\hline Scarus niger & 3 & 0 & 0 & 0 & 0 & 2 & 0 & 5 \\
\hline Chlorurus sordidus & 1 & 0 & 0 & 0 & 0 & 2 & 0 & 0 \\
\hline Siganus corallinus & 0 & 1 & 0 & 2 & 3 & 0 & 4 & 0 \\
\hline Total biomass & 0 & 2 & 1 & 0 & 0 & 1 & 4 & 0 \\
\hline Acanthurus nigrofuscus & 2 & 2 & 1 & 0 & 0 & 2 & 3 & 0 \\
\hline Zebrasoma scopas & 0 & 0 & 0 & 2 & 0 & 1 & 0 & 4 \\
\hline Scarus frenatus & 0 & 2 & 1 & 0 & 0 & 0 & 3 & 0 \\
\hline Scarus niger & 3 & 1 & 0 & 0 & 1 & 0 & 0 & 3 \\
\hline Chlorurus sordidus & 0 & 0 & 0 & 0 & 0 & 1 & 0 & 0 \\
\hline \multirow[t]{4}{*}{ Total } & $11(9)$ & $12(10)$ & $5(3)$ & $8(6)$ & $4(3)$ & $16(13)$ & $20(18)$ & $1.7(15)$ \\
\hline & \multicolumn{4}{|c|}{ Live coral cover } & \multicolumn{4}{|c|}{ Coralline algal cover } \\
\hline & \multicolumn{2}{|c|}{ Impacted } & \multicolumn{2}{|c|}{ Control } & \multicolumn{2}{|c|}{ Impacted } & \multicolumn{2}{|c|}{ Control } \\
\hline & Positive & Negative & Positive & Negative & Positive & Negative & Positive & Negative \\
\hline Total numbers & 4 & 0 & 0 & 0 & 2 & 1 & 2 & 0 \\
\hline Acanthurus nigrofuscus & 4 & 0 & 0 & 0 & 3 & 2 & 2 & 0 \\
\hline Zebrasoma scopas & 3 & 0 & 5 & 0 & 1 & 0 & 4 & 0 \\
\hline Scarus frenatus & 4 & 0 & 0 & 1 & 0 & 1 & 2 & 0 \\
\hline Scarus niger & 0 & 1 & 1 & 0 & 1 & 1 & 0 & 2 \\
\hline Chlorurus sordidus & 1 & 0 & 0 & 2 & 0 & 0 & 2 & 0 \\
\hline Siganus corallinus & 0 & 0 & 0 & 2 & 0 & 2 & 0 & 0 \\
\hline Total biomass & 4 & 0 & 0 & 1 & 2 & 1 & 2 & 0 \\
\hline Acanthurus nigrofuscus & 3 & 0 & 0 & 1 & 2 & 2 & 2 & 1 \\
\hline Zebrasoma scopas & 2 & 0 & 5 & 0 & 1 & 0 & 4 & 0 \\
\hline Scarus frenatus & 4 & 0 & 1 & 1 & 0 & 1 & 2 & 0 \\
\hline Scarus niger & 0 & 1 & 1 & 0 & 0 & 2 & 0 & 2 \\
\hline Chlorurus sordidus & 3 & 0 & 0 & 0 & 0 & 0 & 2 & 0 \\
\hline Total & $32(28)$ & $2(2)$ & $13(11)$ & $8(6)$ & $12(10)$ & $13(11)$ & $24(21)$ & $5(4)$ \\
\hline
\end{tabular}

impacted reefs. To the contrary, there were more negative correlations with algal turfs and positive correlations with live coral cover, particularly on impacted reefs. Finally, Acanthurus nigrofuscus showed a distinct cross-shelf pattern in size-frequency distribution which was independent of COTS status of the reef.

\section{DISCUSSION}

Large-scale natural disturbances such as crown-ofthorns starfish outbreaks provide excellent opportunities for testing ecological hypotheses requiring massive manipulations beyond the ability of investigators (Wellington \& Victor 1985). The extent of and damage from COTS outbreaks on the GBR have indeed been massive, spanning two and a half decades and almost
10 degrees of latitude (Reichelt et al. 1990). In the central region of the GBR where this study was undertaken, $76 \%$ of the reefs were estimated to have experienced an outbreak of Acanthaster planci during the period 1984 to 1989 (Moran et al. 1990).

As a measure of the response of fish communities to these changes, this project simultaneously estimated density and biomass of herbivorous species of fish, as well as quantifying the extent of the algal food resource (Hart \& Klumpp 1996) and the fish-habitat relationship. To date, similar studies have been restricted to 1 or 2 reefs (Sano et al. 1984, 1987. Wass 1987, Carpenter 1990b), or a number of small patch reefs (Robertson 1991). Only Williams (1986) has undertaken a similar comparison on a scale: involving more than 3 reefs, although his focus was at the scale of entire fish communities (Table 5). 


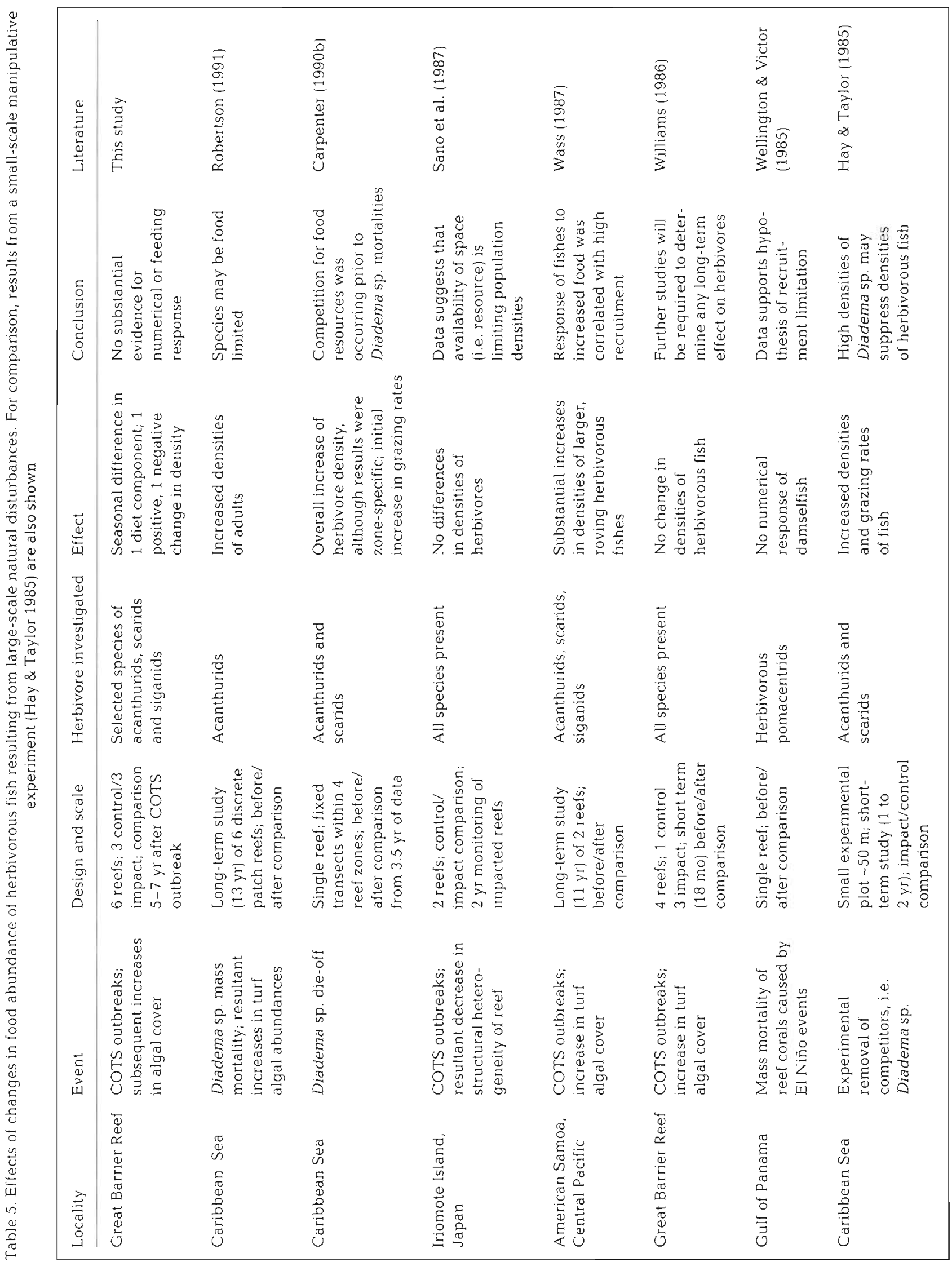


We found little evidence to indicate that, on COTS impacted reefs, herbivorous fish have responded numerically in a positive manner to an increased food resource. Out of 14 variates investigated, only 2 (biomass of Acanthurus nigrofuscus and density of Siganus corallinus) showed any evidence of a numerical response which was positively correlated with a COTS outbreak. Most importantly, total number of individuals and total biomass showed no response. Instead, a negative effect (i.e. higher abundances on control reefs) was detected for Zebrasoma scopas, although this was principally attributable to very high abundances on Coil Reef. Also, the differences in abundance and biomass of $S$. corallinus and A. nigrofuscus between affected and non-affected reefs, albeit significant, were not large (27 and $14 \%$ respectively). Given that, on average, cover of turf algae on impacted reefs was 2.5 to 3 times higher than on non-impacted reefs (Hart \& Klumpp 1996), these large differences in food availability have not been strongly reflected by increases in density and biomass of these 2 species. Moreover, with the exception of $S$. vulpinus, the analysis was able to detect relatively small differences in density and biomass estimates with more than adequate power $(1-\beta)$.

These results are in contrast to Wass (1987), who found an increase in roving herbivorous fish numbers over a $7 \mathrm{yr}$ period following a COTS outbreak in American Samoa. Wass (1987) concluded that the local abundance of adults reflected the carrying capacity and prevalence of algae, although high recruitment occurred at all sites. The conflicting results of all studies on effects of changes in food abundance on herbivorous fishes serve to highlight the arbitrary dichotomy between recruitment and resource limitation in coral reef fish (Jones 1991, Doherty \& Fowler 1994). Wass (1987) was able to demonstrate increased numbers resulting from increased food resources because of an initial high recruitment pulse which occurred at all sites. Thus, both recruitment and postrecruitment process (see Jones 1991) were acting synergistically to bring about a response to an increased resource. This may explain the differences in post-COTS results in Japan (Sano et al. 1987) and the GBR (Williams 1986, this study) vis-a-vis American Samoa (Wass 1987).

Williams (1986) and Sano et al. (1987) detected no numerical response of herbivorous fish to COTS outbreaks (Table 5). Despite this, Williams (1986) suggested that over a longer time scale, change in other processes may affect abundances. For example, growth rates of adults, fecundity, and susceptibility to predation could vary with the modification of the benthic habitat. Growth rates and fecundity of Acanthurus nigrofuscus are presently being investigated (Hart \&
Russ in press). In the case of Sano et al. (1987), substantial, but not significant decreases in mean abundance of some herbivores occurred. Sano et al. (1987) clearly showed that structural heterogeneity of the reef had been reduced into a flat rubble configuration. This resulted from physical and biological erosion of the coral skeleton (mainly Acropora sp.) after the living tissue had been consumed by Acanthaster sp. (Sano et al. 1987). Thus, availability of shelter from potential predators certainly declined, and may have contributed to the decreases in mean abundance.

Evidence of recruitment limitation in damselfish was invoked by Wellington \& Victor (1985), who examined both densities and size frequency distributions. They hypothesised that if a numerical response had occurred, a large proportion of smaller size classes would have been observed. In the present study, an increase in numbers of smaller parrotfish did occur in the final survey (March 1993) at Grub and Centipede reefs, contributing significantly to overall higher abundances of herbivores in March 1993. However, since Grub was impacted and Centipede was not, this cannot be interpreted as evidence of a numerical response to increased food. More likely, it may have been a recruitment pulse consistent across the spatial scale separating these reefs $(-10 \mathrm{~km})$. This phenomenon has been well documented for damselfish (Doherty \& Williams 1988, Doherty \& Fowler 1994) and coral trout (Ferreira $\&$ Russ in press).

For Acanthurus nigrofuscus a greater proportion of individuals occurred in the larger size class (15 to $18 \mathrm{~cm}$ fork length) on the mid-shelf reefs. On outershelf reefs, size distribution was dominated by lower size classes. The effect was most pronounced on Coil, where the majority of individuals occurred in the 9 to $12 \mathrm{~cm}$ size range. Correlations with incident wave energy have been suggested to influence cross-shelf patterns in abundance (Williams 1982, Russ 1984) and are also likely to affect growth rates and subsequent size. Food availability (i.e. algal turfs) and quality is also likely to differ in a cross-shelf manner (Scott \& Russ 1987, Klumpp \& McKinnon 1989). Coil, for example, had the lowest cover of turf algae of all study reefs, while the mid-shelf reefs generally supported higher biomass of turf algae. In addition to having generally higher abundances of algal turfs, mid-shelf reefs also supported far fewer numbers of $A$. nigrofuscus. Thus, density-dependent effects on feeding and growth as a result of intraspecific interactions, known to have major effects on adult numbers and population structure (Jones 1991), are less likely to occur. A. nigrofuscus may live up to 25 yr (Hart \& Russ in press). Initial growth rates are, however, very rapid and an individual is likely to attain maximum size and sexual maturity at 2 to 4 yr. On mid-shelf reefs with an abun- 
dance of food, fewer intraspecific competitors, and a generally less harsh environment in terms of wave energy to inhibit growth, $A$. nigrofuscus is likely to grow to maximum possible size very quickly and live for a long time. This may explain why a large proportion of $A$. nigrofuscus were represented in the larger size classes. On Coil reef, wave energy is higher, food less abundant in terms of percentage cover, and intraspecific competition more likely because of higher numbers. These factors are likely to be contributing to the disparity in size frequency occurring between mid-shelf and outer-shelf reefs

\section{Summary and conclusions}

In this large-scale and detailed comparison of crownof-thorns impacted and control reefs, limited evidence of a numerical or biomass response was detected. This is in concordance with results from Hart \& Klumpp (1995), where no differences in feeding rates or diets of Acanthurus nigrofuscus were found between COTS affected and non-affected reefs. Furthermore, despite a much higher percentage cover of turf algae on impacted reefs, the species investigated showed negative correlations with thick turf algae on these reefs. Additionally, smaller sizes of $A$. nigrofuscus occurred on the outer shelf reefs, which may be due to a combination of physical (wave energy) and biological (food availability and intraspecific competition) phenomena. In the case of A. nigrofuscus, this is currently being examined more thoroughly with a comparison of growth rates, size-at-age and age-at-maturity at these reefs (Hart \& Russ in press).

Acknowledgements. This project was funded by a COTSREC (Crown-of-Thorns Starfish Research Committee) Ph.D. scholarship to A.M.H., administered by the Great Barrier Reef Marme Park Authority, with logistical support from AIMS. The authors thank the many volunteer research assistants, principally Rod Forbes and Dave Hocking. Special thanks to the crew of the R.V. 'Harry Messel', who made the field excursions safe and enjoyable, and to the anonymous referees for thelr pertinent comments. This is contribution No. 727 from the Australian Institute of Marine Science.

\section{LITERATURE CITED}

Bak RPM (1985) Recruitment patterns and mass mortalities in the sea-urchin Diadema antillarum. Proc 5th int. Coral Reefs Congr 5:267-272

Bouchon-Navaro Y, Harmelin-Vivien ML (1985) Impact of coral degredation on a chaetodontid fish assemblage (Moorea, French Polynesia). Proc 5th int Coral Reefs Congr 5:427-432

Carpenter RC (1988) Mass mortality of a Caribbean echinoid immediate effects on community metabolism and other herbivores. Proc natl Acad Sci USA 85:511-514
Carpenter RC (1990a) Mass mortality of Diadema antillarum. I. Long-term effects on sea urchin population dynamics and coral reef algal communities. Mar Biol 104:67-77

Carpenter RC (1990b) Mass mortality of Diadema antillarum. Il. Effects on population densities and grazing intensity of parrotfishes and surgeonfishes. Mar Biol 104:79-86

Connell JH (1978) Diversity in tropical rain forests and coral reefs. Sclence 199:1302-1310

de Ruyter van Steveninck ED, Bak RPM (1986) Changes in abundance of coral-reef bottom components related to mass mortality of the sea urchin Diadema antillarum. Mar Ecol Prog Ser 34:87-94

Doherty PJ, Fowler AJ (1994) An empirical test of recruitment limitation in coral reef fish. Science 263:935-939

Doherty PJ, Williams DMCB (1988) The replenishment of coral reef fish populations. Oceanogr mar Biol A Rev 26:487-551

Ferreira BP, Russ GR (in press) Population structure of the coral trout Plectropomus leopardus on fished and unfished reefs off Townsville, central Great Barrier Reef, Australia. Fish Bull US

Hart AM, Klumpp DW (1996) Response of herbivorous fishes to crown-of-thorns starfish outbreaks. I. Substratum analysis and feeding ecology of Acanthurus nigrofuscus and Scarus frenatus. Mar Ecol Prog Ser 132:11-19

Hay ME, Taylor PR (1985) Competition between herbivorous fishes and urchins on Caribbean reefs. Oecologia 65: $591-598$

Hughes TP (1989) Community structure and diversity of coral reefs: the role of history. Ecology 70:275-279

Hughes TP, Keller BD, Jackson JBC, Boyle MJ (1985) Mass mortality of the echinoid Diadema antillarum Phillipi in Jamaica. Bull mar Sci 36:377-384

Hughes TP, Reed DC, Boyle MJ (1987) Herbivory on coral reefs: community structure following mass mortalities of sea urchins. J exp mar Biol Ecol 113:39-59

Jones GP (1991) Postrecruitment processes in the ecology of coral reef fish populations: a multifactorial perspective. In: Sale PF (ed) The ecology of coral reef fishes. Academic Press, California, p 294-328

Karlson RH, Hurd LE (1993) Disturbance, coral reef communities, and changing ecological paradigms. Coral Reefs 12 $117-125$

Klumpp DW, McKinnon AD (1989) Temporal and spatial patterns in the primary production of a coral reef epilithic algal community. J exp mar Biol Ecol 131:1-22

Klumpp DW, Polunin NVC (1989) Partitioning of food resources between grazers within damselfish territories on a coral reef. J exp mar Biol Ecol 125:145-169

Lessios HA (1988a) Mass mortality of Diadema antillarum in the Caribbean: what have we learned? A Rev Ecol Syst 19:371-393

Lessios HA (1988b) Population dynamics of Diadema antillarum (Echinodermata: Echinoidea) following mass mortality un Panamá. Mar Biol 99:515-526

Lessios HA, Robertson DR, Cubit JD (1984) Spread of Diadema mass mortality through the Caribbean. Science 226 : $335-337$

Liddell WD, Ohlhorst SL (1986) Changes in benthic community composition following the mass mortality of Diadema at Jamaica. J exp mar Biol Ecol 95:271-278

Moran PJ, De'ath G, Baker VJ, Bass DK, Christie CA, Johnson DB, Miller IR, Miller-Smith BA, Mundy CN, Thompson AA (1990) Broadscale surveys of crown-of-thorns starfish and corals along the Great Barrier Reef: 1982-1990. Australian Institute of Marine Science, Townsville

Pickett STA. White PS (1985) Patch dynamics: a synthesis. In Pickett STA, White PS (eds) The ecology of natural distur- 
bance and patch dynamics Academic Press, Orlando, p $371-384$

Polunin NVC, Klumpp DW (1992) Algal food supply and grazer demand in a very productive coral-reef zone. J exp mar Biol Ecol 164:1-15

Reichelt RE, Bradbury RH, Moran PJ (1990) Distribution of Acanthaster planci outbreaks on the Great Barrier Reef between 1966 and 1989. Coral Reefs 9:97-103

Robertson DR (1991) Increases in surgeonfish populations after mass mortality of the sea urchin Diadema antillarum in Panamá indicate food limitation. Mar Biol 111:437-444

Russ GR (1984) Distribution and abundance of herbivorous grazing fishes in the central Great Barrier Reef. II. Patterns of zonation of mid-shelf and outershelf reefs. Mar Ecol Prog Ser 20:35-44

Russ GR (1987) Is rate of removal of algae by grazers reduced inside territories of tropical damselfishes? J exp mar Biol Ecol 110:1-17

Sammarco PW (1983) Effects of fish grazing and damselfish territoriality on coral reef algae. I. Algal community structure. Mar Ecol Prog Ser 13:1-14

Sano $M_{i}$ Shimizu $M_{i}$ Nose $Y(1984)$ Changes in structure of coral reef communities by destruction of hermatypic corals: observational and experimental views. Pacif Sci 38:51-79

Sano M. Shimizu M, Nose $Y$ (1987) Long term effects of the destruction of hermatypic corals by Acanthaster planci

This article was submitted to the editor infestction on reef fish communities at Iriomote Island, Japan. Mar Ecol Prog Ser 37:191-199

Scott FJ, Russ GR (1987) Effects of grazing on species composition of the eprlithic algal community on coral reefs of the central Great Barrier Reef. Mar Ecol Prog Ser 39:293--304

Wass RC (1987) Influence of Acanthaster-induced coral kills on fish communities at Fagatele Bay and at Cape Larsen In: Birkeland C, Randall RH, Wass RC, Smith BD, Wilkins $S$ (eds) Blological resource assessmenit. of the Fagatele Bay National Marine Sanctuary. NOAA Tech Memo NOS MEMD 3. United States Department of Commerce. p 193-209

Wellington GM, Victor BC (1985) El Niño mass coral mortality: a test of resource limitation on a coral reef damselfish population. Oecologia 68:15-19

Wilkinson CR, Sammarco PW (1983) Effects of fish grazing and damselfish territoriality on coral reef algae. II. Nitrogen fixation. Mar. Ecol Prog Ser 13:15-19

Williams DMCB (1982) Patterns in the distribution of fish communities across the central Great Barrier Reef. Coral Reefs $1: 35-43$

Williams DMcB (1986) Temporal variation in the structure of reef slope fish (central Great Barrier Reef): short-term effects of Acanthaster planci infestation. Mar Ecol Prog Ser 28:157-164

Zar JH (1984) Biostatistical analysis, 2nd edn. Prentice-Hall, Englewood Cliffs, NJ

Manuscript first received: November 2, 1994

Revised version accepted: September 14, 1995 